\title{
Transient elevation of ST-segment due to pneumothorax and pneumopericardium
}

\author{
Rodrigo Martins Brandãoa , Amanda Cristina Maria Aparecida Gonçalves ${ }^{\mathrm{b}}$, \\ Renata Paula Martins Brandão ${ }^{c}$, Lucas Fernandes de Oliveiraa ${ }^{a}$ \\ Antonio Carlos Nogueira ${ }^{a}$, Vitor Sérgio Kawabata ${ }^{a}$
}

Brandão RM, Gonçalves ACMA, Brandão RPM, Oliveira LF, Nogueira AC, Kawabata VS. Transient elevation of STsegment due to pneumothorax and pneumopericardium. Autopsy Case Rep [Internet]. 2013;3(1): 63-6. http://dx.doi. org/10.4322/acr.2013.009

\section{ABSTRACT}

\begin{abstract}
ST-segment elevation, observed in the critically ill patients, almost always raises the suspicion of ischemic heart disease. However, nonischemic myocardial and non-myocardial problems in these patients may also lead to ST-segment elevation. Pneumothorax and pneumopericardium have been rarely reported as a cause of transient ST-segment elevation. The authors report the case of a patient admitted to the emergency care unit because of a respiratory failure requiring mechanical ventilatory support. As the patient showed signs of clinical deterioration, a pneumothorax was clinically diagnosed. Chest radiography after thorax drainage also disclosed a pneumopericardium. The 12-lead electrocardiogram recorded before the thoracic drainage revealed an ST-segment elevation, which normalized after the surgical procedure. Ischemic myocardial biomarkers were negative. The authors call attention to the right-sided pneumothorax associated with pneumopericardium as an unusual cause of ST-segment elevation.
\end{abstract}

Keywords: Electrocardiography; Pneumothorax; Pneumopericardium; Asthma; Barotrauma.

\section{CASE REPORT}

A 47-year-old female patient was admitted to the emergency department with a 3-day history of dyspnea, cough, and wheezing. She denied fever and other complaints. She referred a past medical history of asthma and hypertension and was taking an inhaled bronchodilator and a corticosteroid.

On physical examination, the patient was alert, oriented, and hydrated. The blood pressure $(B P)=150 / 80 \mathrm{mmHg}$, pulse rate $=152$ beats per minute, respiratory rate $=32$ respiratory movements per minute $(\mathrm{rmpm})$. The patient looked distressed using the accessory muscles of breathing during inspiration, and the room air pulse oximetry was $88 \%$. Lung examination showed diffuse highpitched expiratory wheezes. The initial diagnosis was bronchospasm caused by an asthma attack.

She was promptly treated with corticosteroids, magnesium sulphate, and inhaled bronchodilators. Non-invasive ventilation was attempted with continuous positive airway pressure of $10 \mathrm{~cm} \mathrm{H} 2 \mathrm{O}$, followed by orotracheal intubation and mechanical ventilatory support.

\footnotetext{
a Department of Internal Medicine - Hospital Universitário - Universidade de São Paulo, São Paulo/SP - Brazil.

${ }^{\mathrm{b}}$ Nursing Department - Hospital Israelita Albert Einstein, São Paulo/SP, Brazil.

c Department of Nephrology - Hospital Beneficência Portuguesa de São Paulo, São Paulo/SP, Brazil.
}

Copyright $\odot 2013$ Autopsy and Case Reports - This is an Open Access article distributed of terms of the Creative Commons Attribution NonCommercial License (http://creativecommons.org/licenses/by/3.0/) which permits unrestricted non-commercial use, distribution, and reproduction in any médium provided article is properly cited. 
About 20 minutes after intubation, arterial hypotension (BP $=90 / 50 \mathrm{mmHg}$ ) associated with an increase in respiratory rate $(R R=40 \mathrm{rmpm})$, a decrease in the capillary oximetry, jugular venous distension, and hyperresonance on right hemithorax percussion raised the hypothesis of hypertensive pneumothorax. The electrocardiographic tracing on the bedside monitor, acquired at the supine position, showed the presence of ST-segment elevation, confirmed with the 12-lead electrocardiogram, which was characterized by ST-segment elevation of $3 \mathrm{~mm}$ in D2, $6 \mathrm{~mm}$ in D3 and $5 \mathrm{~mm}$ in aVF, accompanied by right axis deviation (SÂQRS $=+100^{\circ}$ ) and small voltage of $R$ wave in V1-V3 (Figure 1).

\section{Emergency thoracentesis and pleural} space drainage were performed followed by immediate improvement in oxygenation parameters accompanied by complete reversal of the ST segment elevation (Figure 2).

Troponin and creatine kinase MB isoenzyme (CK-MB) were within normal limits. Echocardiography was normal.

Chest radiography showed the presence of drained pneumothorax associated with pneumopericardium (Figure 3). The patient was referred to the Intensive Care Unit and was extubated on the fifth day.

\section{DISCUSSION}

The 12-lead electrocardiogram is a low cost diagnostic tool, which is widely available, reliable, safe and easily performed. Its utility is immeasurable, as it is always helpful in the diagnosis of heart-related entities. ${ }^{1}$ Since the beginning of the twentieth century, ECG changes related to pneumothorax have been reported.$^{2-3}$ In this context, the most common ECG changes include right axis deviation, reduced $\mathrm{R}$-wave amplitude in precordial leads, QRS alterations (amplitude changes), and T-wave inversions. ${ }^{3-6}$ Electrocardiographic voltage alternations (electrical alternans) were also reported, as well as ST-segment elevation. . $^{3,-9}$

ST-segment elevation may be observed in healthy people, called normal variants. In a study conducted by the US Air Force with 6014 healthy men (age range of 16-58 years old), the presence of ST-segment elevation was found in $91 \%$ in one or more leads, markedly in $\mathrm{V}_{2}$. This finding declines with age to $30 \%$ for men over the age of 76 years. Among women, the ST-segment elevation of $1 \mathrm{~mm}$ occurs in $20 \%$ and remains unchanged regardless of age. ${ }^{10}$

In abnormal situations, ST-segment elevation is one of the electrocardiographic alterations associated with myocardial ischemia coined as a "current of injury." Moreover, this alteration may also be observed in other clinical entities,

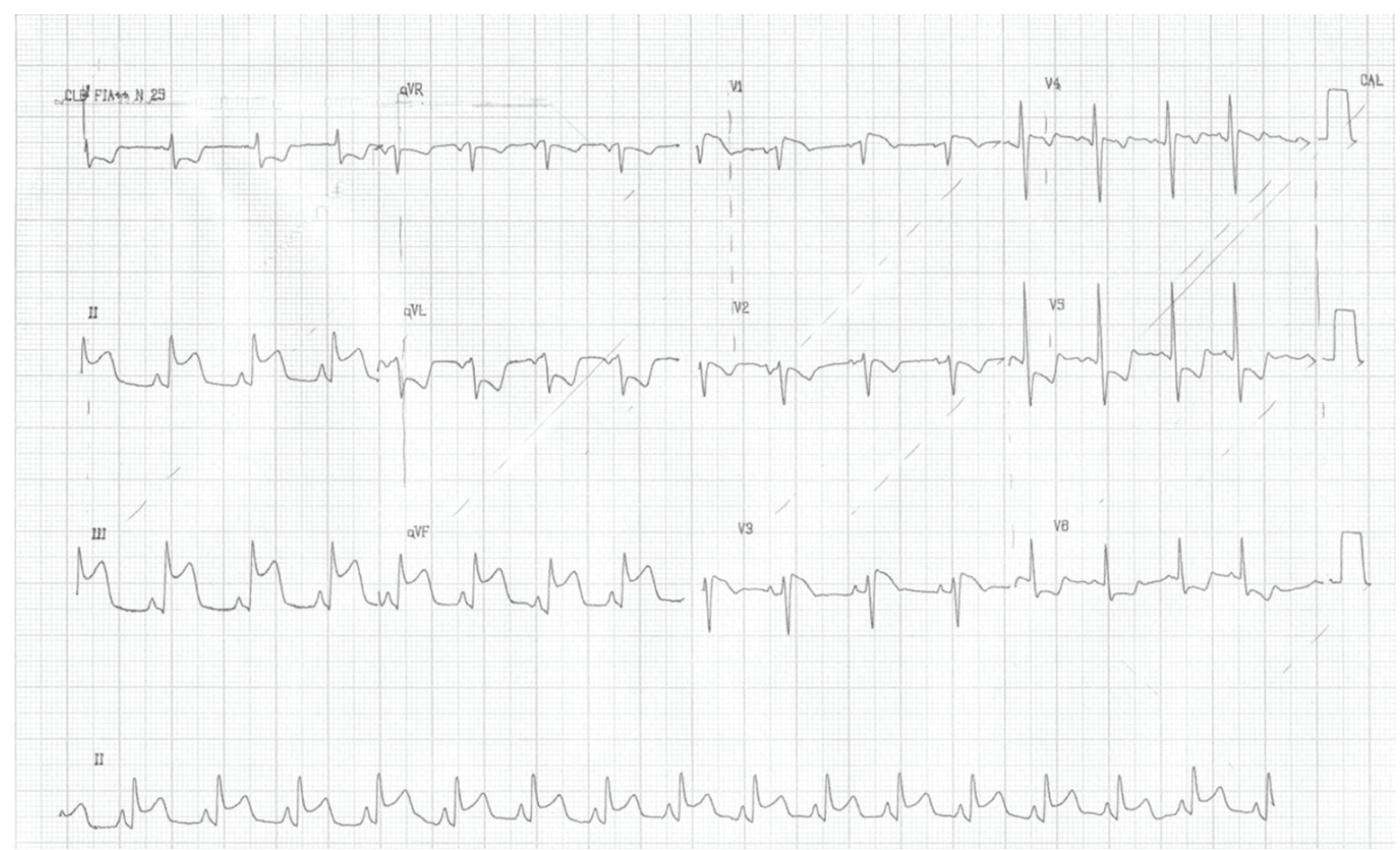

Figure 1 - 12-lead ECG before pleural space drainage, showing sinus rhythm, right axis deviation, small voltage of the $R$ wave in $V_{1}-V_{3}$ and ST-segment elevation $(>3 \mathrm{~mm}$ ). 


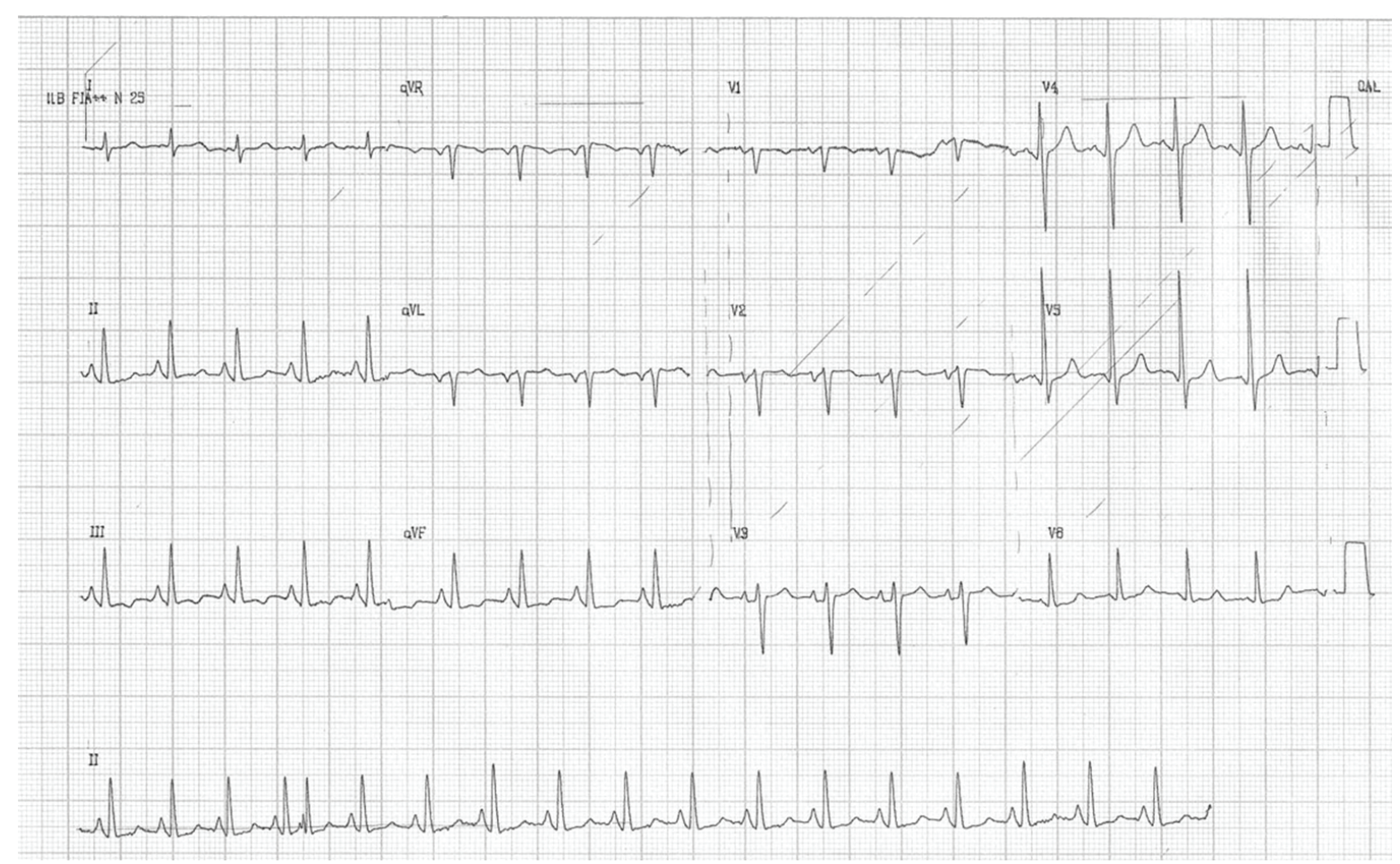

Figure 2 - 12-lead ECG after the pleural space drainage showing normalization of the ST-segment elevation.

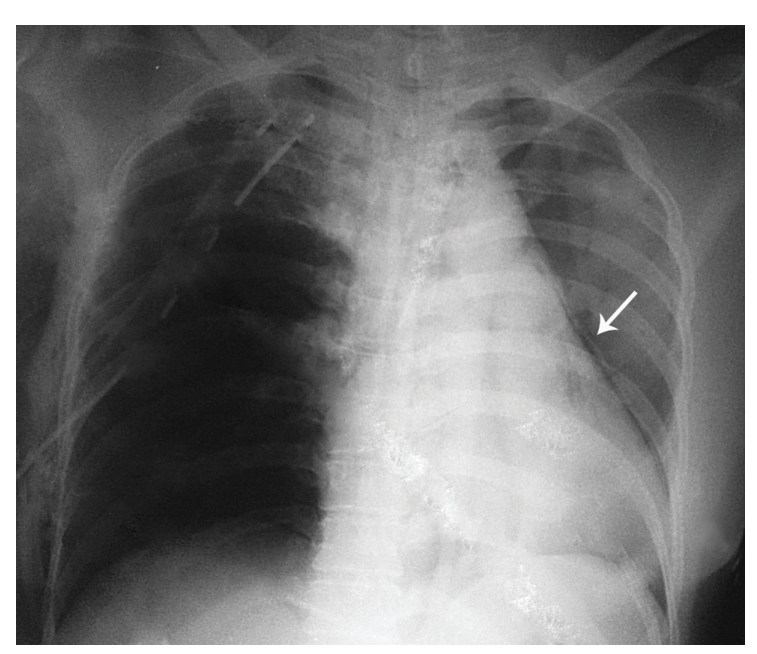

Figure 3 - Posterior-to-anterior chest radiography showing air entrapment in the right hemithorax, with a chest tube inserted, mediastinal shift to the left, with no trachea deviation. Pneumopericardium (arrow) is represented by a thin air layer detaching the pericardium.

such as myocarditis, pericarditis, hyperkalemia, hypothermia, Brugada Syndrome, left ventricular hypertrophy, pulmonary embolism, cardioversion, and Prinzmetal's angina. ${ }^{10}$

Several cases of ST-segment elevation have been described in association with other clinical situations, namely: pneumothorax, pneumopericardium, and pneumoperitoneum without the presence of myocardial injury. ${ }^{1}$ In the cases related to pneumothorax, this ECG change occurs independently of the mediastinal shift, bilateral or unilateral pneumothorax..$^{11,12}$

Few reports exist of ST-segment elevation and they involve older patients with tension pneumothorax and previously known coronary heart disease. ${ }^{3}$

It is suggested that ST-segment elevation and T-wave changes associated with pneumothorax are most likely attributable to transient hypoxia from impaired coronary blood flow, related to the hypotensive state. Other authors suggested that increased intrapleural pressures decreased the cardiac venous return and hence the cardiac preload, leading to decreased stroke volume. Tachycardia ensues to maintain cardiac output. The patient's tachycardia would further increase myocardial oxygen demand, potentially leading to ischemia from underlying vessel disease. ${ }^{3}$

Many other reasons to explain these findings include clockwise cardiac rotation, compressive changes in the right ventricle and ventricular dilation (due to increased resistance in the pulmonary vessels), extrinsic compression of the right coronary artery, hypoxemia, and low cardiac output.,13 Slay et al. ${ }^{14}$ were the first to report the association of pneumothorax and ST-segment elevation, and Brearley et al. ${ }^{4}$ report the ST-segment elevation associated to pneumopericardium. 
In the case reported here, the presence of severe underlying respiratory disease and sudden distress, and the close temporal relationship with the development of ST-segment elevation associated to normalization after pleural space drainage and negative myocardial biomarkers, make the diagnosis of myocardial infarction less likely.

Reports of ST-segment elevation are most commonly described when pneumothorax occurs on the left side. ${ }^{14}$

Krenke et al. ${ }^{15}$ reviewed the ECGs of 40 patients (age range, 18-86 years) admitted with spontaneous pneumothorax (22 left-sided, 18 rightsided), and found only 1 case with T-wave inversion and no cases with ST-segment elevations.

This case report called attention to an unusual cause of ST-segment elevation, quite often related to myocardial infarction, especially among the critically ill patients. It is particularly interesting because of the rare occurrence of ST-segment elevation with pneumopericardium and right-sided pneumothorax.

\section{REFERENCES}

1. Carneiro EF. O eletrocardiograma 10 anos depois. Rio de Janeiro: Enéas Ferreira Carneiro; 1997. p. 75-87. Portuguese.

2. Master AM. The electrocardiographic changes in pneumothorax in which the heart has been rotated. Am Heart J. 1928;3:472-83. http://dx.doi.org/10.1016/S00028703(28)90392-0

3. Shiyovich A, Vladimir Z, Nesher L. Left spontaneous pneumothorax presenting with ST-segment elevations: A case report and review of the literature. Heart Lung. 2011;40:8891. http://dx.doi.org/10.1016/j.hrtlng.2010.09.007

4. Brearley Junior WD, Taylor III L, Haley MW, Littmann L. Pneumomediastinum mimicking acute ST-segment elevation myocardial infarction. Int J Cardiol. 2007;117:73-5. http:// dx.doi.org/10.1016/j.jjcard.2006.11.156

5. Soltani P, Malozzi CM, Saleh BA, Omar B. Eletrocardiogram manifestation of spontaneous pneumothorax. Am J Emerg Med. 2009;27:750 e1-5.

6. Walston A, Brewer DL, Kitchens CS, Krook JE. The electrocardiographic manifestations of spontaneous left pneumothorax. Ann Intern Med. 1974;80:375-9.

7. Anderson R, Costello B, Kilpatrick D. Transient ST-segment elevation resembling acute myocardial infarction in a patient with a right secondary spontaneous pneumothorax. Heart Lung Circ. 2012 Jul 13; [Epub ahead of print; cited 2012 Dec 1]. Available from: http://www.sciencedirect.com/science/ article/pii/S144395061201089X

8. Kounis NG, Mallioris CN, Karavias D, Zavras G, Siablis D. Unusual electrocardiographic changes in intrathoracic conditions. Acta Cardiol. 1987;42:179-85.

9. Kuritzky P, Goldfarb AL. Unusual electrocardiographic changes in spontaneous pneumothorax. Chest. 1976;70:535-7. http:// dx.doi.org/10.1378/chest.70.4.535

10. Wang K, Asinger RW, Marriott HJL.ST-segment elevation in conditions other than acute myocardial infarction. $\mathrm{N}$ Engl J Med. 2003;349:2128-35. http://dx.doi.org/10.1056/ NEJMra022580

11. Monterrubio Villar J, Fernández Bergés D, Alzugaray Fraga RJ, Veiga MD, Córdoba López A, Corcho Díaz G. ST elevation in tension pneumothorax. Rev Esp Cardiol. 2000;53:467-70.

12. Price JW. Novel electrocardiographic changes associated with iatrogenic pneumothorax. Am J Crit Care. 2006;15:415-9.

13. Azzarelli S, Amico F, Giacoppo M, Argentino V, Fiscella D, Fiscella A. Transitorio sopraslivellamento del tratto ST causato da pneumoperitoneo iatrogeno. G Ital Cardiol. 2011;12:2178. Italian

14. Slay RD, Slay LE, Luehrs JG, Houston FS. Transient ST elevation associated with tension pneumothorax. JACEP.1979;8:16-8. http://dx.doi.org/10.1016/S0361$1124(79) 80442-6$

15. Krenke R, Nasilowski J, Przybylowski T, Chazan R. Electrocardiographic changes in patients with spontaneous pneumothorax. J Physiol Pharmacol. 2008;59(Suppl 6):361-73.

\section{Conflict of interest: None}

Submitted on: $21^{\text {st }}$ December 2012

Accept on: $14^{\text {th }}$ February 2013

Correspondence: Divisão de Clínica Médica

Av. Prof. Lineu Prestes, 2565 - Cidade Universitária - São Paulo/SP - Brazil

CEP: 05508-000 - Phone: +55 (11) 3091-9433

E-mail: r.m.brandao@bol.com.br 